\title{
Research Square \\ Outer trench slope extension to frontal wedge compression in a subducting plate
}

\section{Emmy Tsui-Yu CHANG ( $\nabla$ etychang@ntu.edu.tw )}

National Taiwan University https://orcid.org/0000-0002-9886-7643

\section{Laetitia Mozziconacci}

National Taiwan Ocean University

\section{Research Article}

Keywords: Ocean-bottom seismometer, seismic velocity model, near-field focal mechanism solution, northern Manila Trench, overpressure, outer trench slope

Posted Date: January 13th, 2022

DOI: https://doi.org/10.21203/rs.3.rs-1240712/v1

License: (1) This work is licensed under a Creative Commons Attribution 4.0 International License. Read Full License 


\section{Abstract}

Faulting in subducting plates is a critical process that changes the mechanical properties the subducting lithosphere and serves as a carrier of surface materials into mantle wedges. Two intraplate earthquake sequences located in the northern Manila subduction system were investigated in this study, which revealed distinct fault planes but a contrasting seismogeny over the northern Manila Trench. The seismic sequences analyzed in this study were of small-to-moderate events. The events were separately acquired by two ocean-bottom seismometer networks deployed on the frontal accretionary wedge in 2005 and the outer trench slope in 2006. The retrieved seismicity in the frontal wedge (in 2005) mainly included the overpressured sequence, whereas that in the approaching plate (in 2006) was aftershocks of an extensional faulting sequence. The obtained seismic velocity models and $V_{p} / V_{s}$ ratios revealed that the overpressure was likely caused by dehydration within the shallow subduction zone. By using the nearfield waveform inversion algorithm, we determined focal mechanism solutions for a few relatively large earthquakes. Data from global seismic observations were also used to conclude that stress transfer may be responsible for the seismic activity in the study area in 2005-2006. In late 2005, the plate interface in the frontal wedge area was unlocked by overpressure effect with the thrusting-dominant sequence. This event changed the stress regime across the Manila Trench and triggered the normal fault extension at the outer trench slope in mid-2006. However, the hybrid focal solution indicating reverse and strike-slip mechanisms provided in this study revealed that the plate interface had become locked again in late 2006 .

\section{Introduction}

Subducting slabs are considered the primary avenue through which fluid is transported into the Earth's mantle. Lithological fractures in the incoming plate and that are filled with unconsolidated water-rich sediments are considered potential fluid carriers; these fractures cause the mineral hydration of subduction systems (e.g., Peacock 1990; Audet et al. 2009, 2013; Obana et al. 2012; Han et al. 2016; Faccenda et al. 2009; Faccenda 2014; Grevemeyer et al. 2018). Insertion of fluid into the lithosphere may trigger crustal eclogitization or mantle serpentinization, changing the mechanical structure of these regions during subduction (Schlaphorst et al. 2016). The mechanical properties of lithospheric fractures in subduction zones-which are affected by the lithospheric thickness, chemical composition, and the tectonic evolution of the plate-are crucial for the consequent processes in the subducted slab and mantle wedge.

In this study, we conducted a near-field seismic observation in the northern Manila subduction system to investigate faulting around the trench. In the study area, the South China Sea (SCS) seafloor is actively subducting beneath the Philippine Sea (PS) plate (Figure 1). The Manila subduction system is situated between Taiwan and Luzon, and the plate convergent rate is approximately $100 \mathrm{~mm} / \mathrm{yr}$ near North Luzon but is reduced to $50+\mathrm{mm} / \mathrm{yr}$ near Taiwan due to the collision of the PS plate against the Eurasian plate (Yu et al. 1999; Galgana et al. 2007). The magnetic anomaly in the central basin of the SCS indicates that seafloor spreading took place during the Oligocene to early Miocene (32-10 Ma) periods in a north- 
south symmetric expansion (e.g., Taylor and Hayes 1983; Briais et al. 1993). Seismic profiles in the northern SCS reveal the relicts of the initial continental rifting, and continental crust thinning in the northern SCS can be further inferred (e.g., Wang et al. 2006; Cullen et al. 2010; Mclntosh et al. 2013, 2014; Eakin et al. 2014). The continent-ocean boundary in the northern SCS has not yet been identified. On the basis of the time scales of the magnetic anomaly, the northeast SCS between the Eurasian continental margin and the Manila Trench has been determined to have the oldest crust in the SCS (Hsu et al. 2004; Briais et al. 1993). Analyses of lithospheric mechanical strength by conducting flexural modeling have revealed significant variation in mechanical behavior for the subducting lithosphere (J. Zhang et al. 2018; F. Zhang et al. 2018; Li et al. 2019). The continent-ocean transition and weakening of the plate by flexural bending cause variation in lithospheric strength around the Manila Trench. Thus, the joint mechanism of basin spreading and plate subduction in the northeast SCS may generate local structures that indicate varied tectonic processes at different temporal and spatial scales.

We analyzed two earthquake groups occurring on opposite sides of the northern Manila Trench. Seismic data were acquired from seafloor networks of ocean-bottom seismometers (OBSs) independently deployed in 2005 and 2006. These networks are denoted Network 2005 and Network 2006, respectively. Network 2006 was located on the outer trench slope of the incoming SCS plate west of the Manila Trench (Figure 1). Network 2005 was located east of the position of Network 2006 and was distributed across the Manila Trench and the frontal area of the Taiwan accretionary prism (Figure 1). Bathymetry for both networks indicated that their depths were approximately $4000 \mathrm{~m}$ on average.

Because they had limited battery capacity, both OBS networks only recorded data for less than one week. Network 2005 was active from October 7 to 11, 2005, on the seafloor and comprised five short-periodresponse OBSs. Network 2006 was active from November 20 to 26, 2006, and had nine OBSs. Detailed station information is presented in Table S1. Although the spatial aperture and duration of these experiments were limited, hundreds to thousands of earthquakes were recorded during the two experiments (Figures 2 and 3). The resolved seismicity from carefully refined velocity models illustrates the distinct fault geometries that extend through the crust and lithospheric mantle within the subducting SCS plate. The ratio of P- to S-wave velocity, $V_{\mathrm{p}} / V_{\mathrm{S}}$, is sensitive to lithological strength and water content (e.g., Domenico 1984; Christensen 1996). The high $V_{p} / V_{s}$ ratios retrieved from the earthquake groups detected by Network 2005 indicate high water content within the top layers in the frontal accretionary area. We further determined the focal mechanism solutions by using the near-field waveform inversion method (Delouis 2014) for a few of the larger events in these two sequences to investigate the stress regime. Our results provide a close look at the seismic properties of the upper portion of the lithosphere in the subduction zone. A sharp change in the seismogeny over the Manila Trench was discovered, and a triggering of earthquakes due to fluid overpressure in the frontal accretionary prism was identified.

\section{Seismicity In The Northern Manila Subduction Zone From Global Networks}


The tectonic units in subduction between Taiwan and Luzon are, from west to east, the Manila Trench, the frontal wedge of the accretionary prism, the forearc basins, and the Luzon Volcanic Arc (Figure 1). Approximately 3400 events are archived in the USGS global earthquake catalog (https://earthquake.usgs.gov/earthquakes/search/) for this area. Most are moderate earthquakes with magnitudes ranging from 3.0 to 5.0. The Wadati-Benioff zone corresponding to eastward subduction of the SCS can be identified to a depth of $200 \mathrm{~km}$ in northern Luzon, where it becomes shallower and less active as it approaches the Taiwan orogen (seismicity Profiles S1, S2, and S3 in Figure 1). Apart from that in the Wadati-Benioff zone, most of the seismic activity between Taiwan and Luzon is in a few earthquake clusters distributed beneath the volcanic arc and in the forearc basin. Based on the Global CMT mechanism solutions (https://www.globalcmt.org/), these seismic clusters correspond to significant lateral shortening due to the thrusting and strike-slip mechanisms (Figure 1).

In both global earthquake catalogs (USGS and Global CMT), seismic activity over the northern Manila trench is minor. Figure 2 illustrates the temporal evolution of the seismicity within the area in which Networks 2005 and 2006 were deployed. It reveals sparse seismic activity from 1945 to December 2021. The USGS catalog indicates that only one sequence occurred at the outer trench slope during the period from the middle to the end of 2006 is noticeable (Figure 2). The Global CMT mechanism solutions indicate that this sequence is due to normal fault deformations with the fault planes parallel to the trench axis (Figure 1 and Figure S1 in the supplementary material). This is consistent with other normal fault observations at the outer trench slope because the upper layer of the oceanic crust is under extensional stress caused by downward bending of the subducting lithosphere (e.g., Jones et al. 1978; Hilde 1983). The USGS catalog chronicles that this earthquake sequence began in May 2006. The earthquakes detected by Network 2006 in November are the aftershocks of this outer trench slope sequence.

Within the coverage area of Network 2005, the GCMT provides three normal-fault-dominant focal mechanism solutions for the events inside Network 2005. However, data from the Taiwanese broad-band seismic network (https://tecws1.earth.sinica.edu.tw/AutoBATS/) indicates a deformation in thrusting with strike-slip motion for the main shock of this sequence (more details are provided in the supplementary material Figure S1). By using data from Network 2005, we determined that the mechanism underlying the earthquakes detected by the network is a compound mechanism comprising both thrusting and strike-slip deformation. In the following sections, we describe a distinct seismic pattern in the near-field OBS observations of the trench area.

\section{Near-field Obs Observations Over The Northern Manila Trench}

The OBS instruments used in this study were short-period seismometers (MicrOBS) supplied by the L'Institut Français de Recherche pour l'Exploitation de la Mer. The MicrOBS data logger is stable and efficiently recorded ground motion in the frequency band of $1-100 \mathrm{~Hz}$ with a peak response at $4.5 \mathrm{~Hz}$ (Auffret et al. 2004). Seismic airgun shots proceeded OBS deployments to relocate the seafloor OBS stations and to retrieve the recording directions of the two horizontal components (Chang et al. 2008). 
Prior to the outer trench slope sequence that occurred in 2006, we had already deployed Network 2005 at the lower slope of the frontal wedge in 2005 to detect the seismicity in the trench area. We used a standard seismic program, HYPOINVERSE2000 (Klein 2002), to determine the earthquake hypocenters detected by using the OBS networks. The initial velocity model (Figure 4) is based on Eakin et al. (2014: Profile T2, Figure 11). With hypocentral determination with the initial velocity model, we refined the seismic velocity layer by layer from top to bottom by minimizing the travel-time residuals and iteratively relocating the earthquakes. The program VELEST (Kissling et al. 1994) was employed to retrieve the optimized velocity model with each OBS experiment. Events with a travel-time residual larger than $0.3 \mathrm{~s}$, approximately $5 \%$ of the detections, were removed. Ultimately, approximately 400 and 2400 local earthquakes were retrieved from the campaign records of Networks 2005 and 2006, respectively. We hereafter refer to these two earthquake groups as C2005 and C2006, respectively. The hypocentral parameters of C2005 and C2006 are listed in Table S2. The temporal evolution of these groups is presented in Figure 2. Figure 3 presents a map view of the seismicity density (per $\mathrm{km}^{2}$ ) at various focal depth levels. In this study, zero focal depth indicates sea level.

In accordance with the spatial range of focal depths, the retrieved seismic models defined the velocity structures approximately 25 and $35 \mathrm{~km}$ below the seafloor for Networks 2005 and 2006, respectively. Because unconsolidated sediments are distributed across the seafloor, we allowed for, but did not preset, a low-velocity layer in the topmost kilometers when developing the velocity models. Figure 4 presents the layered seismic models generated from $\mathrm{C} 2005$ and $\mathrm{C} 2006 ; V_{\mathrm{p}} / V_{\mathrm{s}}$ was evaluated in terms of depth. These two seismic velocity models appear to be consistent with oceanic crust rather than continental crust. However, the velocity model determined using C2005 indicates a structure of dipping downgoing oceanic crust with low-velocity sedimentary rocks in the top layers. The seismic parameters of these two groups of earthquakes are presented in detail as follows.

C2005: Earthquakes in the frontal wedge of the overriding plate

C2005 comprised earthquakes occurring over a period of 5 days (October 7-11). A mainshock of magnitude 4.5 occurred on October 9 (Event 67 in Table S2) and was recorded by Network 2005 at a depth of approximately $9 \mathrm{~km}$. Before this event, microseisms were scattered within the shallow layers at approximately $5 \mathrm{~km}$ (Figure 2). The seismicity increased simultaneously with the emergence of the mainshock, and the focal depth distribution of C2005 was dramatically extended to approximately $25 \mathrm{~km}$ from sea level (Figure 2). The accurate hypocentral determination reveals that this sequence was distributed in a spatially vertical zone over a depth range of $20 \mathrm{~km}$. This type of spatial pattern is not commonly detected in the subduction zone. In the frontal wedge area, seismicity usually indicates a regime of hydrologic and tectonic processes with active faults. However, the seismogenic zone was recognized by a décollement dividing an upper brittle-fracture-dominated domain overlying a lower, ductile domain. Pore-water geochemical evidence reveals that along-fault flow occurs specifically in the upper brittle domain but is hydrologically isolated from fluids in the underlying footwall sediments (e.g., Cello and Nurr 1988; Tobin et al. 2001; Lin Andrew et al. 2009). The C2005 data indicate vital seismic activity in which the up-thrust faulting emerged at the top crust of the frontal wedge area. 
The seismic velocity model constructed with C2005 indicated low velocity for the top layers within $4 \mathrm{~km}$ from the seafloor. The P- and S-wave velocities are approximately $<3.0$ and $<1.8 \mathrm{~km} / \mathrm{s}$, respectively, and $V_{p} / V_{s}>1.80$. In particular, in the topmost layer $(\sim 1 \mathrm{~km})$ the P-and S-wave velocities are as low as 1.9 and $0.6 \mathrm{~km} / \mathrm{s}$, respectively. $V_{\mathrm{p}} / V_{\mathrm{s}}$ for this layer is 1.83 . This low-velocity impedance is common in unconsolidated sediments at shallow accretionary prisms. Network 2005 was located in a field of widely distributed gas hydrate in southwest offshore Taiwan (e.g., Liu et al. 2006; Berndt et al. 2019). Thus, a high $V_{\mathrm{p}} / V_{\mathrm{s}}$ at the topmost layer was expected. At the depth of $4 \mathrm{~km}$ beneath than the seafloor, the $\mathrm{P}$ - and S-velocities are much higher at approximately 5.8 and $3 \mathrm{~km} / \mathrm{s}$, respectively. This sharp change in seismic velocity corresponds to the interface between accretionary sediments and hard basement. However, the $V_{\mathrm{p}} / V_{\mathrm{s}}$ ratio remains as large as 1.80 at the upper and lower layers of the sediment-hard rock interface (Figure 4). We considered high fluid content at the interface as well as in the accretionary sediments in the frontal area. Notably, this is the depth level at which where we observed microseisms before the mainshock of Event 67; it is also the focal depth of the larger earthquakes (including the mainshock) of this sequence. We inferred, therefore, that the upper layers, comprising the sedimentary prism and the top crust, have high fluid content, and overpressure of this fluid is responsible for the earthquake sequence beginning on October 9 .

Below $9 \mathrm{~km}$, the seismic velocity increases and $V_{\mathrm{p}} / V_{\mathrm{s}}$ decreases until approximately $16 \mathrm{~km}$. At depths below $16 \mathrm{~km}$, the seismic velocity is almost invariant; the P-wave velocity is approximately $7.8-8.0 \mathrm{~km} / \mathrm{s}$. However, $V_{p} / V_{s}$ increases to 1.75 from 16 to $20 \mathrm{~km}$. This may indicate a change in lithology from oceanic crust to lithospheric mantle. The Moho depth at the frontal wedge site should be approximately $16 \mathrm{~km}$ below the sea level, as revealed by the C2005 data.

C2006: Earthquakes in the outer trench slope of the coming plate

Network 2006 was located on the outer trench slope west of the Manila Trench, and earthquake magnitudes in $\mathrm{C} 2006$ ranged from 1 to 3.5 without temporal or spatial variation during the experimental period (Figure 2). However, the seismicity rate in C2006 was as high as 500 events per day. Combining our result with the global seismic observations reveals that this bending-extensional sequence lasted for months-at least from the middle to the end of 2006.

The hypocenters in C2006 reveal two fault planes at different depth ranges: a high-angle north-south striking fault plane dipping to the northeast and located from the seafloor to approximately $25 \mathrm{~km}$ and a low-angle fault plane lying at approximately 20-35 km (Figure 3). C2006 were the aftershock events of the extensional sequence initialized in the middle of 2006. Both GCMT and AutoBATS indicate a northsouth striking normal fault for the large events of this sequence (Figures 1 and S1). We recognize that the high-angle northeastward-dipping fault plane revealed by C2006 is the actual fault plane of this normal fault sequence. However, few clues regarding the formation mechanism for this low-angle fault with extensional deformation of the plate have been obtained. Based on the seismic velocities obtained in C2006, the Moho depth should be approximately $8 \mathrm{~km}$ below the seafloor ( $12 \mathrm{~km}$ below sea level); at and below this depth, the P-wave velocity was as much as $7.6 \mathrm{~km} / \mathrm{s}$ and invariant. This Moho depth 
reading is consistent with the previous active seismic surveys in this area (e.g., Wang et al. 2006; Eakin et al. 2014; Lester et al. 2014) In the other words, the low-angle fault plane is deformation in the upper mantle.

Because the northeast SCS contains relict structures from primitive basin spreading, we infer that the lowangle fault in C2006 is the deep detachment fault, which is the lowest bound of the listric normal faults that form in the hyperextension (Reston et al. 1996).

In addition to information about the Moho depth, the seismic velocity model from C2006 also indicates a relatively low lithological strength for the oceanic plate (Figure 4). The P-velocity at the topmost layer is approximately $3.8 \mathrm{~km} / \mathrm{s}$, indicating sedimentary rock or hard rock. However, $V_{\mathrm{p}} / V_{\mathrm{s}}$ at these layers is greater than 1.80. This may indicate mechanical weakening or hydro fractures in the outer trench slope area caused by extensional fractures or indicate the filling of the fractures by sediments with high fluid content, or both (e.g., Tobin et al. 2014).

Furthermore, the $V_{\mathrm{p}} / V_{\mathrm{s}}$ ratios from C2006 are lower than those from C2005 at the layers above $20 \mathrm{~km}$, indicating that the dehydration is dramatic as the plate subducts into the mantle.

\section{Focal Mechanism Solutions Determined By Near-field Waveform Inversion}

We used the FMNEAR program to determine the focal mechanism solutions for the 29 larger earthquakes detected by our OBS networks. FMNEAR implements a near-field waveform inversion scheme to obtain focal mechanism solutions when there are few seismic stations. The detailed FMNEAR algorithm was described by Delouis (2014; http://source.unice.fr:8080/ FMNEAR/). In practice, seven focal parametersthe strike, dip, rake, rupture velocity $\left(V_{r}\right)$, slip (dislocation, $\Delta u$ ), and relative coordinates of the hypocenter and rupture center of the fault plane-are used in FMNEAR. Because the earthquakes detected in our experiment were all of small-to-moderate magnitude, the focal energy was assumed to have been emitted from a single point source. We also assumed that the rupture propagated circularly with constant velocity on the fault planes and assumed that the source time function was a simple ramp defined by a constant rise time $(\tau)$ and slip. Although the focal mechanisms of the small events were not substantially affected by the rise time, we adopted the empirical relationship proposed by Sommerville et al. (1999), $\tau=\Delta u / V_{r}$ and used a simple $V_{r}$ of $1 \mathrm{~km} / \mathrm{s}$. Combining the equation of seismic moment scaling (Hanks and Kanamori 1979) and the relationship of coseismic slip ( $\Delta u)$ with seismic moment, the slip $\Delta u$ was determined as follows:

$$
\Delta u=\frac{10 \frac{3}{2}\left(M_{W}+10.7\right)}{\mu L^{2}}
$$


where $\mu$ is the rigidity coefficient, equal to $3.5 \times 10^{11} \mathrm{dyne} / \mathrm{cm}^{2}$, and $L^{2}$ is the square of the rupture length. For all types of fault plane slipping, $L^{2}$ was obtained from the empirical relationship of the moment magnitude from Wells and Coppersmith (1994):

$$
\log L^{2}=-3.49+0.91 M_{W}
$$

2

Therefore, the parameters $\Delta u, L$, and $\tau$ could be determined a priori for the inversion. The waveform segment was taken from $3 \mathrm{~s}$ before the P-wave arrival until the end of the earthquake signal. The original waveform was integrated into the displacement and then treated using a bandpass filter of the remaining main motion signals. This process was then iteratively undertaken for various fault parameters (i.e., strike, dip, and rake). The waveform fittings were conducted using the optimal seismic parameters obtained through the near-field waveform inversion. Five large earthquakes from C2005 and C2006 are presented in Figure S2 to demonstrate the statistics of the fitting residuals and the synthetic waveforms in inversion. The retrieved focal mechanism solutions are presented in Table S3 and illustrated in Figure 5 .

In this study, the focal mechanism solutions determined from C2005 are those of relatively large events located at a depth of approximately $9 \mathrm{~km}$. Those for $\mathrm{C} 2006$ are from the earthquakes forming the northsouth-striking, high-angle fault plane and distributed in a depth range of 5-25 km; no solutions were obtained for the lower fault plane. The compressive $(P)$ and tensional $(T)$ axes are presented with their projections on the surface in Figure 5. We further determined the stress regimes by using these focal solutions. Álvarez-Gómez's (2019) focal mechanism classification program was used to perform clustering analysis of the data and to generate a double-couple classification diagram through the Kaverina projection technique (Kaverina et al. 1996). The resulting mechanical classification is presented in Figure 5.

Figure 5 reveals that the seismic mechanisms of C2005 and C2006 included not only thrusting failures but also significant strike-slip deformations. These solutions indicate high-angle fault planes associated with the seismic geometries. In Figure 5, the P-axes derived from C2005 indicate an oblique-to-parallel orientation to the surface trace of the trench. Their principal direction follows the plate collision of the PS plate moving northwestward toward the Eurasian plate. However, these retrieved P-axes indicate a wide range of stress azimuths. This pattern may have been due to the uncertainty in our inversion.

However, analysis of C2006 indicates that the stress regime in the approaching plate is a strong strikeslip failure with the reverse mechanism. The distribution of the P-and T-axes of these solutions does not correspond to the extensional mechanism pattern of the outer trench slope area. In fact, the P- and T-axes retrieved from C2006 vary in space (see Figure 5). Some solutions are even oriented oblique-toperpendicular to the Manila Trench. 


\section{Discussion And Conclusion}

Our results reveal that the seismic activity level in marine convergent boundaries is far beyond the monitoring capacity of terrestrial seismic networks. By contrast with the high-magnitude tsunamigenic earthquakes occurring on subducting plate interfaces, the earthquakes detected in our study were intraplate earthquakes with small-to-moderate magnitude. These events reveal the distinct seismotectonic properties of lithospheric deformation during subduction: the C2006 earthquakes were from a series of months-long aftershock events in the outer trench slope, whereas the C2005 earthquakes were primarily triggered by fluid overpressure in the frontal wedge area. Figure 6 presents the seismogenic patterns revealed in the above analyses as a schematic lithospheric cross-section of the subducting SCS plate. The spatial distribution of $\mathrm{C} 2006$ events reveals that the high-angle fault plane at the outer trench slope develops through the crust and upper lithospheric mantle; whereas the low-angle fault plane in the approaching plate lies in the lithospheric mantle. These two fault planes merge at a depth of approximately $30 \mathrm{~km}$. In $\mathrm{C} 2006$, the $V_{\mathrm{p}} / V_{\mathrm{s}}$ ratio indicates a weakening fracture in the topmost layer of the approaching plate. However, the hydrofracture effect does not seem to influence the lower crust or the upper mantle before the plate subducts into the mantle.

The crustal thickness was determined from the velocity model over approximately $8 \mathrm{~km}$ for the approaching plate as well as for the subducted slab. The velocity structure in the frontal area corresponds to a downgoing dipping slab of sedimentary prism with a low velocity in the upper $4 \mathrm{~km}$. The relatively large $V_{\mathrm{p}} / V_{\mathrm{s}}$ ratio through the crust level and the vertically penetrating seismicity reveal substantial effects caused by fluid in the slab beneath the frontal area. However, the stress inversion conducted from the two groups (mostly from the shallow events) reveals a significant thrusting component in both the $\mathrm{C} 2005$ and C2006 events. The contrast in seismogeny of these two groups indicates possible temporal and fluid effects in this region; these are discussed separately in the following subsections.

\subsection{Possible stress transferring within the northern Manila subduction system}

The capacity of terrestrial stations to detect offshore seismic events is limited. Within the spatial frame of our two OBS networks, only one sequence (in 2006) was detected by the global seismic network in recent years. Combining the spatial and temporal seismogenic patterns from our result and the global catalog indicates that stress transfer may be responsible for the seismic activity in the study area in 2005-2006. In late 2005, overpressure in the frontal wedge unlocked the plate interface and triggered the thrustingdominant sequence on October 9. This event changed the stress regime across the Manila Trench and triggered the normal fault extension at the outer trench slope in mid-2006. However, the hybrid focal solution of C2006 indicating reverse and strike-slip mechanisms revealed that the plate interface had become locked again in late 2006 , and the regional stress was restored to laterally oblique convergence. 
Remarkably, C2006 also reveals a distinct stress variation from the extension of the mainshock to the post-deformation lateral convergence. In fact, Obana et al. (2012) reported a similar observation for events on the outer slope of the Japan Trench. They discovered that the stress regime of the high-angle faults on the outer slope had temporal variation before and after the 2011 Tohoku earthquake. Variations in spatial and temporal stress range transferred between a subducted slab and approaching plate remain poorly understood in subduction zone research; more observations of offshore earthquakes should be performed to better understand this topic.

\subsection{Dehydration in the warm Manila subduction zone}

Water is carried into the mantle by subducting slabs. However, whether fluids originate from local dehydration reactions or from up-dip transportation from greater depths is unknown. The depths at which fluids are released from metamorphic dehydration reactions are a function of the pressure-temperature $(\mathrm{P}-\mathrm{T})$ path of the plate boundary, which varies significantly between subduction zones (e.g., Syracuse et al. 2010; van Keken et al. 2018). Condit et al. (2020) reported that a series of major dehydration reactions are predicted to occur at shallower depths in relatively warm subduction zones; these reactions cause fault slip behaviors such as nonvolcanic tremor and episodic slow slip events that have been observed below the seismogenic zone of a number of subduction plate boundaries (Dragert et al. 2001; Obara 2002; Rogers and Dragert 2003). Laboratory friction experiments have demonstrated that materials dominated by framework minerals, such as feldspar, have higher frictional strength but velocityweakenng properties that enable the nucleation of seismic ruptures during fracturing (e.g., lkari et al. 2011; Saffer and Wallace 2015). Dehydration-induced breakage of basalt is also predicted to persist up to temperatures higher than $300^{\circ} \mathrm{C}$.

Our study reveals that the $\mathrm{C} 2005$ events were mainly triggered by fluid overpressure at the top of the crust. The $V_{\mathrm{p}} / V_{\mathrm{s}}$ ratios in $\mathrm{C} 2005$ are much higher than those in C2006 in both the crust and the uppermost mantle levels, indicating that dehydration has an effect when the plate underplates beneath the accretionary prism. Thus, local dehydration reactions are likely the main mechanism underlying overpressure in the frontal wedge of the Manila subduction system. The northern Manila subduction zone is likely a warm subduction zone even though a significant microseism, as shown in this study, has not been reported in recent years.

Furthermore, the seismicity of C2005 indicates an overpressure explosion through the entire crust levelnot only along the plate interface. Our results support the conclusion that fluid release from thermodynamically constrained metamorphic reactions occurs at shallow depths (i.e., $<30 \mathrm{~km}$ depth) in the warm subduction model, resulting in a fluid-oversaturated subduction channel at the base of the forearc crust, as previously indicated by numerical modeling (Menant et al. 2019). We posit that punctuated dehydration of the oceanic crust provides the dominant source of fluid at the base of the seismogenic zone in these warm subduction zones, and up-dip migration of fluids from deeper in the subduction zone is not required. 


\section{Abbreviations}

SCS: South China Sea

PS: Philippine Sea

OBS: ocean-bottom seismometer

COB: continent-ocean boundary

MT: Manila Trench

\section{Declarations}

\section{- Availability of data and materials}

The seismic parameters (hypocenter, focal mechanism solution) are provided in the file "supplementary materials".

\section{- Competing interests}

There are no conflicts of interest to declare.

\section{- Funding}

Ministry of Science and Technology, Taiwan, MOST 110-2611-M-002-012 -

\section{- Authors' Contributions}

Emmy T. Chang: Conceptualization, Investigation, Data curation, Writing/original draft preparation, Visualization, Project administration

Laetitia Mozziconacci: Methodology, Software

\section{Acknowledgment}

The authors are grateful for the kind support for the OBS instrumentation by the Institute of Applied Geoscience, National Taiwan Ocean University and support for the deployment by the crew of Ocean Research Vessel I (Institute of Oceanography, National Taiwan University). This study benefited substantially from the visit of the first author to JAMSTEC in 2019. The figures were prepared using the GMT software and with help from Haofang Hsueh and Fangyi Lee. This study is supported by the

\section{References}


1. Álvarez-Gómez JA (2019) FMC-Earthquake focal mechanisms data management, cluster and classification. SoftwareX 9:299-307

2. Audet P, Bostock MG, Christensen NI, Peacock SM (2009) Seismic evidence for overpressured subducted oceanic crust and megathrust fault sealing. Nature 457:76-78

3. Audet P, Schwartz SY (2013) Hydrologic control of forearc strength and seismicity in the Costa Rican subduction zone. Nat Geosci 6:852-855

4. Auffret Y, Pelleau P, Klingelhoefer F, Crozon J, Lin JY, Sibuet JC (2004) MicrOBS: A new ocean bottom seismometer generation. First Break 22:41-47

5. Berndt C, Chi WC, Jegen M, Lebas E, Crutchley G, Muff S, Holz S, Sommer M, Lin S, Liu CS, Lin AT, Klaeschen D, Klaucke I, Chen L, Hsu HH, Kunath P, Elger J, McIntosh KD, Feseker T (2019) Tectonic controls on gas hydrate distribution off SW Taiwan. J Geophys Res Solid Earth 124(2):1164-1184. https://doi.org/10.1029/2018JB016213

6. Briais A, Patriat P, Tapponnier P (1993) Updated Interpretation of Magnetic Anomalies and Seafloor Spreading Stages in the South China Sea: Implications for the Tertiary Tectonics of Southeast Asia. J Geophys Res Solid Earth 98(B94):6299-6328. https://hal.archives-ouvertes.fr/hal-00552239

7. Chang ETY, Hsu S-K, Lee C-S (2008) Earthquake swarm recorded by an ocean bottom seismic array in southwest offshore of Taiwan in October, 2005. Terr Atmos Ocean Sci 19. https://doi.org/10.3319/TAO.2008.19.6.717(PT)

8. Christensen NI (1996) Poisson's ratio and crustal seismology. J Geophys Res Solid Earth 101:31393156

9. Condit CB, Guevara VE, Delph JR, French ME (2020) Slab dehydration in warm subduction zones at depths of episodic slip and tremor. Earth Planet Sci Lett 552:116601.

https://doi.org/https://doi.org/10.1016/j.epsl.2020.116601

10. Cullen A, Reemst P, Henstra G, Gozzard S, Anandaroop R (2010) Rifting of the South China Sea: new perspective. Pet Geosci 16:273-282

11. Delouis B (2014) FMNEAR: determination of focal mechanism and first estimate of rupture directivity using near source records and a linear distribution of point sources. Bull Seism Soc Am 104(3):1479-1500. https://doi:10.1785/0120130151

12. Domenico SN (1984) Rock lithology and porosity determination from shear and compressional wave velocity. Geophysics 49:1188-1195

13. Dragert $H$, Wang $K$, James TS (2001) A silent slip event on the deeper Cascadia subduction interface. Science 292(5521):1525-1528

14. Eakin DH, Mclntosh KD, Van Avendonk HJA, Lavier L, Lester R, Liu CS, Lee CS (2014) Crustal-scale seismic profiles across the Manila subduction zone: The transition from intraoceanic subduction to incipient collision. J Geophys Res Solid Earth 119(1):1-17. https://doi.org/10.1002/2013jb010395

15. Faccenda M (2014) Water in the slab: A trilogy. Tectonophysics 614:1-30 
16. Faccenda M, Gerya TV, Burlini L (2009) Deep slab hydration induced by bending-related variations in tectonic pressure. Nat Geosci 2(11):790-793. https://doi:10.1038/ngeo656

17. Grevemeyer I, Ranero CR, Ivandic M (2018) Structure of oceanic crust and serpentinization at subduction trenches. Geosphere 14(2):395-418

18. Galgana G, Hamburger M, McCaffrey R, Corpuz E, Chen Q (2007) Analysis of crustal deformation in Luzon, Philippines using geodetic observations and earthquake focal mechanisms. Tectonophysics 432(1-4):63-87

19. Han S, Carbotte SM, Canales JP, Nedimovic MR, Carton H, Gibson JC, Horning GW (2016) Seismic reflection imaging of the Juan de Fuca plate from ridge to trench: New constraints on the distribution of faulting and evolution of the crust prior to subduction. J Geophys Res Solid Earth 121:1849-1872

20. Hanks TC, Kanamori H (1979) A moment magnitude scale. J Geophys Res 84:2348-2350

21. Hilde TW (1983) Sediment subduction versus accretion around the Pacific. Tectonophysics 99(24):381-397

22. Hsu S-K, Yeh Y-C, Doo W-B, Tsai C-H (2004) New bathymetry and magnetic lineations identifications in the northernmost South China Sea and their tectonic implications. Mar Geophys Res 25(1-2):2944

23. Ikari MJ, Niemeijer AR, Marone $C$ (2011) The role of fault zone fabric and lithification state on frictional strength, constitutive behavior, and deformation microstructure. J Geophys Res Solid Earth 116(B8). https://doi.org/https://doi.org/10.1029/2011JB008264

24. Jones G, Hilde T, Sharman G, Agnew D (1978) Fault patterns in outer trench walls and their tectonic significance. Journal of Physics of the Earth 26(Supplement):S85-S101

25. Kaverina AN, Lander AV, Prozorov AG (1996) Global creepex distribution and its relation to earthquake-source geometry and tectonic origin. Geophys J Int 125(1):249-265

26. Klein FW (2002) User's Guide to HYPOINVERSE-2000, a Fortran Program to Solve for Earthquake Locations and Magnitudes: U.S. Geological Survey Open-File Report 02-171, 123 pp

27. Kissling E, Ellsworth WL, Eberhart-Phillips D, Kradolfer U (1994) Initial reference models in seismic tomography. J Geophys Res 99:19635-19646

28. Lester R, Van Avendonk HJA, Mclntosh K, Lavier L, Liu C-S, Wang TK, Wu F (2014) Rifting and magmatism in the northeastern South China Sea from wide-angle tomography and seismic reflection imaging. J Geophys Res Solid Earth 119:2305-2323

29. Li F, Sun Z, Pang X, Liao J, Yang H, Xie H, Zhuo H, Zhao Z (2019) Low-viscosity crustal layer controls the crustal architecture and thermal distribution at hyperextended margins: Modeling insight and application to the Northern South China Sea margin. Geochem Geophys Geosys. https://doi.org/10.1029/2019GC008200

30. Li C-F, Wang P, Franke D, Lin J, Tian J (2012) Unlocking the opening processes of the South China Sea. Sci Drill 14:55-59 
31. Lin AT, Yao B, Hsu S-K, Liu C-S, Huang C-Y (2009) Tectonic features of the incipient arc-continent collision zone of Taiwan: Implications for seismicity. Tectonophysics 479(1):28-42. https://doi.org/https://doi.org/10.1016/j.tecto.2008.11.004

32. Liu C-S, Schnürle P, Wang Y, Chung S-H, Chen S-C, Hsiuan T-H (2006) Distribution and Characters of Gas Hydrate Offshore of Southwestern Taiwan. Terr Atmos Ocean Sci 17(4):615-644

33. McIntosh K, Lavier L, van Avendonk H, Lester R, Eakin D, Liu C-S (2014) Crustal structure and inferred rifting processes in the northeast South China Sea. Mar Pet Geol 58:612-626. https://doi.org/10.1016/j.marpetgeo.2014.03.012

34. McIntosh K, van Avendonk H, Lavier L, Lester WR, Eakin D, Wu F, Liu C-S, Lee C-S (2013) Inversion of a hyper-extended rifted margin in the southern Central Range of Taiwan. Geology 41(8):871-874. https://doi.org/10.1130/g34402.1

35. Menant A, Angiboust S, Gerya T (2019) Stress-driven fluid flow controls long-term megathrust strength and deep accretionary dynamics. Scientific Reports 9(1), 9714. Retrieved 2019/07//, from http://europepmc.org/abstract/MED/31273309

36. Mooney WD, Laske G, Masters TG (1998) CRUST 5.1: A global crustal model at $5^{\circ} \times 5$. J Geophys Res Solid Earth 103:727-747

37. Obana K, Fujie G, Takahashi T, Yamamoto Y, Nakamura Y, Kodaira S, Takahashi N, Kaneda Y, Shinohara M (2012) Normal-faulting earthquakes beneath the outer slope of the Japan Trench after the 2011 Tohoku earthquake: Implications for the stress regime in the incoming Pacific plate. Geophys Res Lett 39:1-7

38. Obara K (2002) Nonvolcanic deep tremor associated with subduction in southwest Japan. Science 296(5573):1679-1681

39. Peacock SM (1990) Fluid processes in subduction zones. Science 248:329-337

40. Reston T, Krawczyk C, Klaeschen D (1996) The S reflector west of Galicia (Spain): Evidence from prestack depth migration for detachment faulting during continental breakup. J Geophys Res Solid Earth 101(B4):8075-8091

41. Rogers G, Dragert H (2003) Episodic tremor and slip on the Cascadia subduction zone: The chatter of silent slip. Science 300(5627):1942-1943

42. Saffer DM, Wallace LM (2015) The frictional, hydrologic, metamorphic and thermal habitat of shallow slow earthquakes. Nat Geosci 8(8):594-600. https://doi.org/10.1038/ngeo2490

43. Schlaphorst D, Kendall J-M, Collier JS, Verdon JP, Blundy J, Baptie B, Latchman JL, Massin F, Bouin M-P (2016) Water, oceanic fracture zones and the lubrication of subducting plate boundaries-insights from seismicity. Geophys J Int 204:1405-1420

44. Somerville P, Irikura K, Graves R, Sawada S, Wald D, Abrahamson N, Iwasaki Y, Kagawa T, Smith N, Kowada A (1999) Characterizing crustal earthquake slip models for the prediction of strong ground motion. Seismol Res Lett 70:59-80

45. Syracuse EM, van Keken PE, Abers GA (2010) The global range of subduction zone thermal models. Phys Earth Planet Inter 183(1-2):73-90 
46. Taylor B, Hayes DE (1983) Origin and history of the South China Sea basin. The Tectonic and Geologic Evolution of Southeast Asian Seas and Islands: Part 2, 90 edited. AGU, Washington, DC, pp 23-56

47. Tobin H, Henry P, Vannucchi P, Screaton E (2014) Subduction zones: structure and deformation history.. In Developments in marine geology, vol 7. Elsevier, pp 599-640

48. Van Avendonk HJA, Davis JK, Harding JL, Lawver LA (2017) Decrease in oceanic crustal thickness since the breakup of Pangaea. Nat Geosci 10:58-61. https://doi.org/10.1038/ngeo2849

49. van Keken PE, Hacker BR, Syracuse EM, Abers GA (2011) Subduction factory: 4. Depth-dependent flux of $\mathrm{H} 2 \mathrm{O}$ from subducting slabs worldwide. J Geophys Res Solid Earth 116(B1). https://doi.org/10.1029/2010jb007922

50. Wang TK, Chen M-K, Lee C-S, Xia K (2006) Seismic imaging of the transitional crust across the northeastern margin of the South China Sea. Tectonophysics 412(3):237-254. https://doi.org/https://doi.org/10.1016/j.tecto.2005.10.039

51. Wells DL, Coppersmith KJ (1994) New empirical relationships among magnitude, rupture length, rupture width, rupture area, and surface displacement. Bull Seismol Soc Am 84:974-1002

52. Yu S-B, Kuo L-C, Punongbayan RS, Ramos EG (1999) GPS observation of crustal deformation in the Taiwan-Luzon Region. Geophys Res Lett 26(7):923-926.

https://doi.org/https://doi.org/10.1029/1999GL900148

53. Zhang F, Lin J, Zhou Z, Yang H, Zhan W (2018) Intra- and intertrench variations in flexural bending of the Manila, Mariana and global trenches: implications on plate weakening in controlling trench dynamics. Geophys J Int 212(2):1429-1449. https://doi.org/10.1093/gji/ggx488

54. Zhang J, Sun Z, Xu M, Yang H, Zhang Y, Li F (2018) Lithospheric 3-D flexural modelling of subducted oceanic plate with variable effective elastic thickness along the Manila Trench. Geophys J Int 215(3):2071-2092. https://doi.org/10.1093/gji/ggy393

55. Zhang, J., Sun, Z., Xu, M., Yang, H., Zhang, Y., Li, F., 2018. Lithospheric 3-D flexural modelling of subducted oceanic plate with variable effective elastic thickness along the Manila Trench. Geophys. J. Int. 215(3), 2071-2092. https://doi.org/10.1093/gji/ggy393

\section{Figures}

\section{Figure 1}

Morphological map of the features of the northern SCS with four seismic cross-sections (S1 to S4). The shading indicates the geological units of the accretionary wedge (yellow), forearc basin (purple), and volcanic arc (light-brown). The red and blue triangles in the map are the locations of the ocean-bottom seismometer (OBS) stations comprising the 2005 and 2006 networks. The four blue lines indicate the locations of the cross-sections (right) displaying the earthquake events (gray dots) between Taiwan and 
Luzon (sourced from the USGS global catalogue). The red and blue dots on the cross-sections are the C2005 and C2006 earthquake sequences, respectively, detected in this study. The focal mechanism solutions were acquired from the Global CMT catalogue for events $>M w 5.5$. Five of the focal mechanism solutions in the 2006 network occurred before 2006, and all had extensional mechanisms. The red-line rectangle denotes the geographical location of the area associated with the data in Figures 2 and 3 . SCS = South China Sea, PS = Philippine Sea, and COB = continent-ocean boundary (Hsu et al. 2004; Briais et al. 1993).

\section{Figure 2}

Graphic illustrating the focal depth distribution of the events as a function of time in the study area (red rectangle in Figure 1). Blue Open circles are the USGS earthquakes events. Two insert figures (a) and (b) show C2005 and C2006 events. The accumulated number and magnitude are provided in (a) and (b). The largest event in C2005 is marked with a red circle, and the occurrence time is indicated by a red dashed line.

\section{Figure 3}

C2005 and C2006 seismicity. (a) Epicentral distribution of the two sequences retrieved in this study. The red and blue triangles are the 2005 and 2006 networks stations, respectively. (b) - (h) Corresponding seismicity intensity per square kilometer at various depth ranges.

\section{Figure 4}

Layered seismic wave (P- and S-waves) velocity models ((a) and (b)) and Vp/Vs ratio versus depth (c). The solid and dashed lines in the velocity models represent the P- and S-wave velocities, respectively. The red and blue lines in the Vp/Vs ratio plot are the value from C2005 and C2006. Both scales of depth from sea level and seafloor are indicated. The velocity models for typical oceanic crusts are adopted from Mooney et al. (1998), shown in (a) with light-brown lines. The initial velocity model (P-wave velocity) is adopted from Eakin et al. (2014), indicated in black line and black-dash line (original curve) in (b).

\section{Figure 5}

(a) Focal mechanism solutions determined in this study. The mechanical P- and T-axes are shown as blue and yellow dots on the beach balls and are projected onto the horizontal surface at their epicentral 
locations. (b-1 and b-2) Mechanical classification diagrams.

\section{Figure 6}

Schematic of a cross-section through the subducting SCS plate. The red and blue dots are the C2005 and C2006 earthquakes, respectively. MT=Manila Trench.

\section{Supplementary Files}

This is a list of supplementary files associated with this preprint. Click to download.

- SupplementaryMaterials.pdf 